\author{
Aleksandar Žic \\ E-mail: aleksandar.zic1@gmail.com \\ Independent researcher, Žardin 6, Punat, Croatia \\ Barbara Pongračić \\ E-mail: bpongracic@iolap.com \\ IOLAP, Inc., 51000 Rijeka, Croatia \\ Serđo Kos \\ E-mail: skos@pfri.hr \\ University of Rijeka, Faculty of Maritime Studies, Rijeka, Croatia \\ David Brčić \\ E-mail: brcic@pfri.hr (corresponding author) \\ University of Rijeka, Faculty of Maritime Studies, Rijeka, Croatia
}

\title{
On GPS L1 Positioning Errors' Estimation in the Adriatic Region
}

\begin{abstract}
Prediction of satellite positioning errors represents a substantial step towards the Global Navigation Satellite System (GNSS) performance assessment. Satellite positioning accuracy in the particular area can be expected to be similar due to prevailing environmental conditions. This similarity opens the opportunity to estimate and predict the positioning errors of close locations. The paper aims to develop a regional model of positioning errors estimation for Global Positioning System (GPS) single-frequency receivers based on ground truth data from reference stations, in this phase considering different levels of space weather activity as one $f$ the criteria defining environmental conditions. The model should provide a simple positioning error prediction in cases where reference stations and respective data do not exist. The space weather conditions were examined to determine the influence on GPS satellite positioning performance at three selected International GNSS Service (IGS) stations in the Adriatic Region - Graz, Padua, and Matera. The mutual relations in terms of positioning error patterns were elaborated. The same 15-day period in three consecutive years was analysed. Pearson's coefficient was utilised as a major indicator for determining the degree of correlation. The data from IGS stations Padua and Graz showed better, significant correlation results. The IGS station Matera, located farther and southward slightly differed in positioning deviations' patterns and was not used for the model development. Satellite positioning errors of IGS Padua were used as a reference to determine the positioning errors of IGS Graz. Due to the significant correlation results, the linear regression model has been developed for the latitude, longitude, and height positioning errors. The final model coefficients were calculated as average values of the model coefficients for latitude, longitude, and height errors for elaborated periods. The cross-validation with five folds has been carried out, showing good model performance with $\mathrm{R}^{2}$ values of 0.7785 for geographic latitude, 0.8132 for the geographic longitude, and 0.7796 for height above sea level, respectively. The validation showed that the model could be applied during all levels of space weather activity on a regional basis.
\end{abstract}

Keywords: GPS single frequency positioning error, IGS network, Adriatic Region, linear regression model, statistical model, space weather indices 


\section{Introduction and background}

GPS L1 receivers are still considered to be the most common satellite positioning devices, providing GNSS based services for a variety of individual and official applications. The satellite positioning error budget encompasses variety of causes, with space weather acting as most prominent, always considering single frequency positioning.

The ionospheric activity in middle latitudes' region acts as a most stable and less vulnerable to outer influences [1,2]. Space weather impacts on satellite positioning have been already investigated in the Adriatic region $[3,4,5]$. Among others, the studies directed the research interest to similarities in positioning error behaviour as observed in the region, indicating mutual relations between relatively close locations. The aim of the research was to estimate positioning errors at locations without reference stations by developing a regional model of GPS L1 positioning errors. The general assumption was that, similar to Differential GNSS (DGNSS) service, the satellite positioning performs in a smaller or greater extent equally under the same regional influential conditions, considering space weather activity.

Positioning solutions from three IGS stations located in the Adriatic region were analysed during 15 days for three consecutive years. Each period was marked with different space weather conditions, which was confirmed with analysis of solar, interplanetary, geomagnetic and ionospheric indices.

In the following chapter, the research methodology is described together with relevant data and indices used for the research. Satellite positioning performance results were presented as a basis for the model construction. The results of model performance and its validation are presented further, together with possibilities for the future development of regional positioning error estimation modelling.

\section{GPS L1 positioning errors' estimation}

The research methodology consists of a selection of geographical area and research periods, collection of relevant data, identification of space weather conditions, statistical analyses of obtained and gained data, development of a regional positioning errors' estimation model and its verification.

The selection of research periods was based on the following criteria: the same calendar period within a year, representative length of a period, consecutive years, presence of different space weather conditions and data availability. 


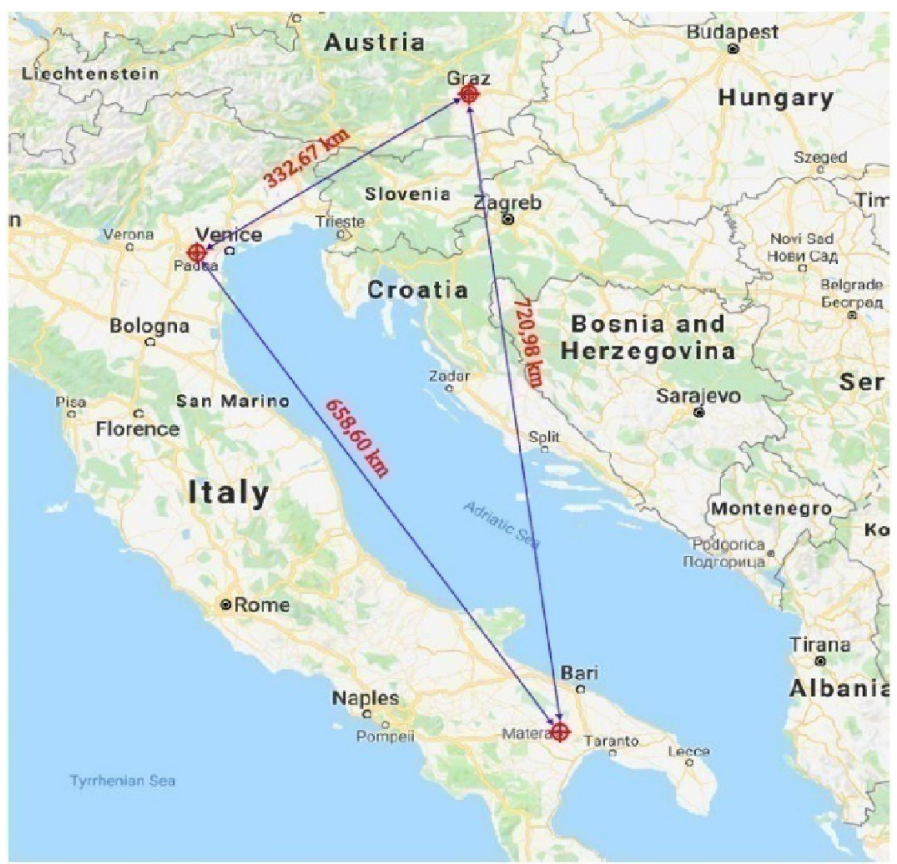

Figure 1-Locations of used IGS stations

The study was conducted in the Adriatic Sea region (middle geomagnetic latitudes) where several International GNSS Service (IGS) reference stations are located, providing necessary data availability for the study: Graz (Austria), Padua (Italy) and Matera (Italy), as shown in Table 1. The elaborated area together with great circle distances between IGS stations is shown in Figure 1.

Daily position solutions for each reference IGS station were computed with RTKLIB, a GNSS SDR software tool configured to perform single-frequency commercial-grade GPS receiver positioning [6]. Positioning solutions were created in post-processing with combination of collected raw GPS observables and navigation messages, both in Receiver INdependent Exchange Format (RINEX) [7,8,9]. Klobuchar ionospheric correction model, as well as the Saastamoinen tropospheric correction model, were applied during the positioning data generation. Mask angle was set to $15^{\circ}$. Daily positioning solutions represent calculated spatial position in $30 \mathrm{sec}$ time resolution for IGS stations during all years. Positioning errors (latitude, longitude and height) were calculated based on station's reference $3 \mathrm{D}$ positions and converted in meters. 
Table 1 - Basic features of used IGS reference stations

\begin{tabular}{|c|c|c|c|c|c|}
\hline $\begin{array}{c}\text { Station } \\
\text { ID }\end{array}$ & $\begin{array}{c}\text { Location } \\
\text { (Country) }\end{array}$ & $\begin{array}{c}\text { Receiver } \\
\text { Model }\end{array}$ & $\begin{array}{c}\text { Geo. } \\
\text { Latitude } \boldsymbol{\varphi} \\
{\left[{ }^{\circ} \mathbf{N}\right]}\end{array}$ & $\begin{array}{c}\text { Geo. } \\
\text { Longitude } \lambda \\
{\left[{ }^{\circ} \mathbf{E}\right]}\end{array}$ & $\begin{array}{c}\text { Height } \\
{[\mathbf{m}]}\end{array}$ \\
\hline Graz & Graz (Austria) & Leica GRX1200+GNSS & 47.0671 & 15.4935 & 538.3 \\
\hline Pado & Padua (Italy) & Septentrio PolaRx5 & 45.4111 & 11.8961 & 64.7 \\
\hline Mate & Matera (Italy) & Leica GR30 & 40.6491 & 16.7045 & 535.6 \\
\hline
\end{tabular}

Space weather conditions were defined by analysing following solar, interplanetary, geomagnetic and ionospheric indices: planetary indices Kp and Ap, Disturbance Storm Time index (Dst), terrestrial and satellite-based geomagnetic field components Bx, By, Bz, SunSpot Number (SSN), solar flux (F10.7) and the Total Electron Content (TEC) $[10,11,12,13]$. Long-term time series analysis of elaborated indices indicated different levels of solar, geomagnetic and ionospheric activity during March in 2015, 2016 and 2017. Further analysis leads to period $10-24$ March (14 days) which encompassed required conditions of solar, geomagnetic and ionospheric activity, according to criteria defined in $[14,15,16]$.

Correlation method was applied on all collected and calculated (space weather and positioning) data with correlation matrices as the presentation of the results. Pearson correlation coefficients were used as follows [17]:

$$
r_{x y}=\frac{\sum_{i=1}^{n}\left(X_{i}-\bar{X}\right)\left(Y_{i}-\bar{Y}\right)}{\sqrt{\sum_{i=1}^{n}\left(X_{i}-\bar{X}\right)^{2}} \cdot \sqrt{\sum_{i=1}^{n}\left(Y_{i}-\bar{Y}\right)^{2}}}
$$

where $r_{x y} \ldots$ Pearson correlation coefficient, $X_{i}-\bar{X}, Y_{i}-\bar{Y}$... deviations from average values.

A positioning error estimation was developed as a linear regression model. Model parameters were optimised using least squares fit. Since the dataset on which the model was built is relatively small, cross-validation was used to assess its performance.

If real response values are $y_{1}, \ldots, y_{n}$ and $n p$-dimensional vector covariates are $x_{1}, \ldots, x_{n}$, the components of the vector $\boldsymbol{x}_{\boldsymbol{i}}$ are denoted as $x_{i 1}, \ldots, x_{i p}$. Least squares are used to fit a function in the form of a hyperplane $\boldsymbol{y}=\hat{\boldsymbol{\beta}}_{0}+\hat{\boldsymbol{\beta}}_{1}^{\mathrm{T}} \boldsymbol{x}$, and the mean squared error (MSE) can be assessed. The MSE for given estimated parameter $\hat{\beta}_{0}$ and $\hat{\beta}_{1}$ on the training set $\left(x_{i}, y_{i}\right)_{1 \leq i \leq n}$, is [18]: 


$$
\frac{1}{n} \sum_{i=1}^{n}\left(y_{i}-\hat{\beta}_{0}-\hat{\beta}_{1}^{T} x_{i}\right)^{2}=\frac{1}{n} \sum_{i=1}^{n}\left(y_{i}-\hat{\beta}_{0}-\hat{\beta}_{1} x_{i 1}-\ldots-\hat{\beta}_{p} x_{i p}\right)^{2}
$$

In $k$-fold cross-validation, the original sample is randomly partitioned into $k$ equally sized subsamples, one used as the validation data for testing the model and the remaining $k-1$ subsamples are used as training data. Process is repeated $k$ times and the $k$ results can then be averaged to produce a single estimation. The coefficient of determination $\left(\mathrm{R}^{2}\right)$ was used as a performance index of regression function data fitting as it shows the proportion of the dependent variable variance predictable by the independent variable.

\section{Results of space weather conditions and positioning performance analyses}

The following section provides summarised results of analysed parameters of space weather activity as well as satellite positioning performance as determined at the IGS stations.

\subsection{Space weather activity}

An overview of solar indices' values through periods is presented in Figure 2. March 2015 was marked with strong solar activities with sunspot number reaching a maximum value of 108. Medium activity was observed during 2016 with 80 sunspots at maximum. During 2017, solar activity was low with $73 \%$ of spotless days. 

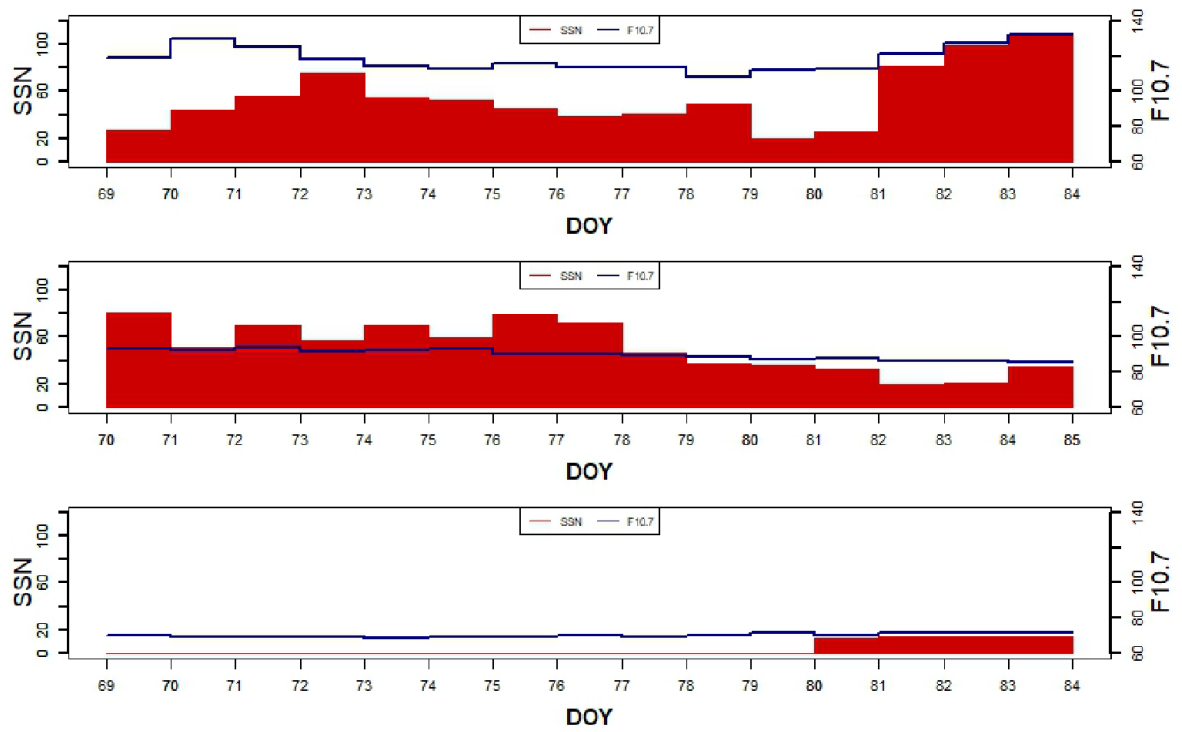

Figure 2 - Solar indices in 2015 (top), 2016 (middle) and 2017 (bottom)

Same solar activities are confirmed with solar radio flux (F 10.7) mean values: $118.4 \mathrm{sfu}$ in 2015, 90.0 sfu in 2016 and $70.2 \mathrm{sfu}$ in 2017.

Geomagnetic activity was evaluated with $\mathrm{Kp}$, Ap, Dst indices and geomagnetic field components measured with magnetometers installed on Chambon la Foret ground station and on-board GOES-15 satellite (Figures 3, 4 and 5). March 2015 was period of rough space weather conditions with peak on 17 March 2015 when the strongest geomagnetic storm of 24th solar cycle occurred. The storm was rated as severe "G4" on NOAA space weather scale with Kp index reaching maximum of 9, Ap value of 179 , Dst index was low as $-223 \mathrm{nT}$, and average solar wind velocity was $550 \mathrm{~km} / \mathrm{s}$. Moderate space weather conditions were observed during 2016 when maximum value of $\mathrm{Kp}$ index was 5 indicating moderate geomagnetic disturbance. Corresponding Ap index was 56, and the lowest value of the Dst index was -56 nT. March 2017 was period of moderate space weather conditions. The highest value of Kp was five, indicating moderate disturbance, while the Dst index was lower than the previous year (-35 nT). Geomagnetic field measured in Chambon la Foret revealed large changes in all three components during a geomagnetic storm on 17 March 2017. 

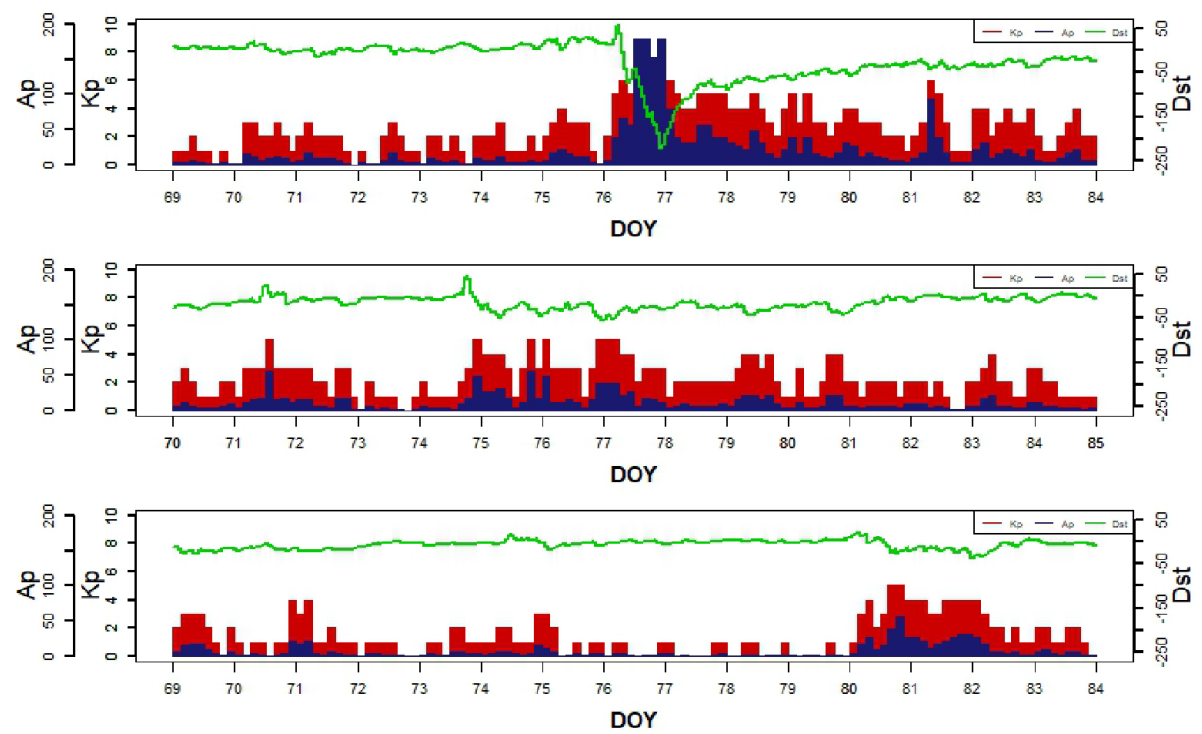

Figure 3 - Geomagnetic indices in 2015 (top), 2016 (middle) and 2017 (bottom)
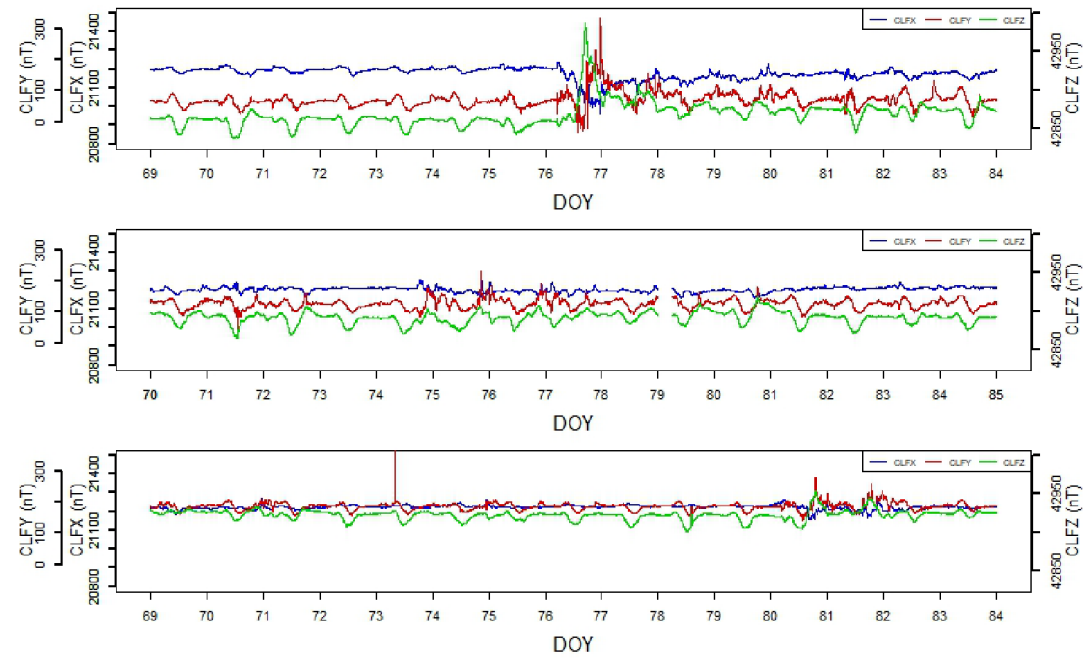

Figure 4 - Ground-based geomagnetic field components (Bx, By, Bz) in 2015 (top), 2016 (middle) and 2017 (bottom) 
Geomagnetic field components measured on board GOES-15 satellite (Figure 5) confirmed geomagnetic storm existence during March 2015. Sudden changes in all components are visible. The Y component of the geomagnetic field showed greatest fluctuations during all years.
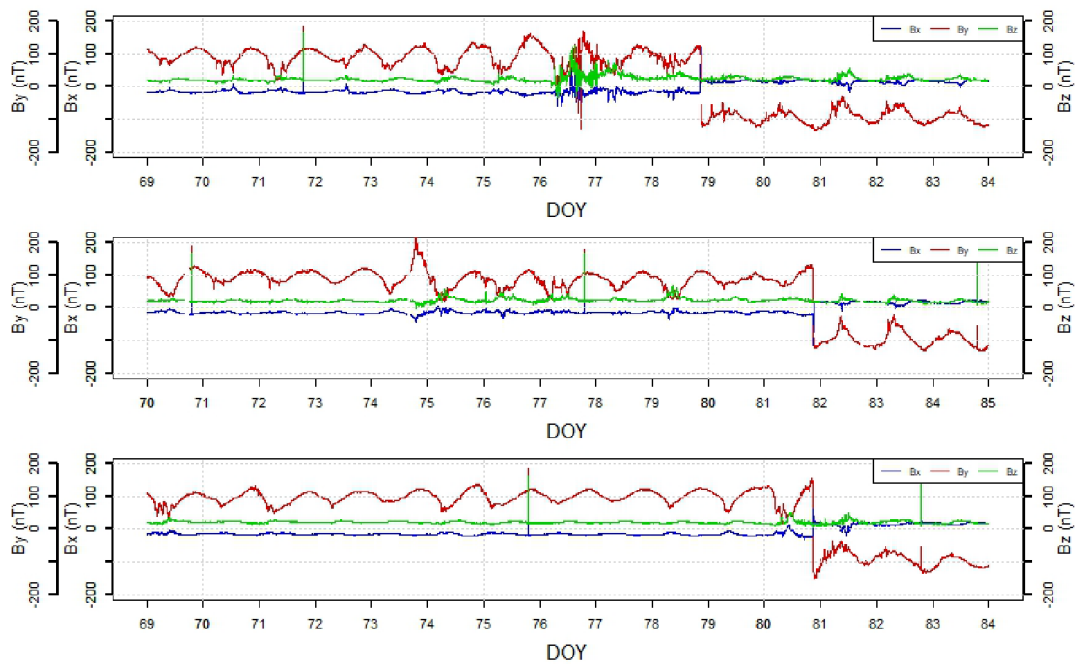

Figure 5 - Satellite-based geomagnetic field components (Bx, By, Bz) in 2015 (top), 2016 (middle) and 2017 (bottom)

The ionospheric activity was evaluated with TEC values (Figure 6). The highest span of TEC values was in 2015 reaching more than 50 TEC units at all three stations. Period of geomagnetic storm is visible when TEC values increased more than other days, and that suggested to disturbed ionosphere. Medium TEC span was in 2016 and during 2017 was the lowest. It was noted that TEC values of Matera station were during 2015 and 2017 slightly larger comparing to other stations. 

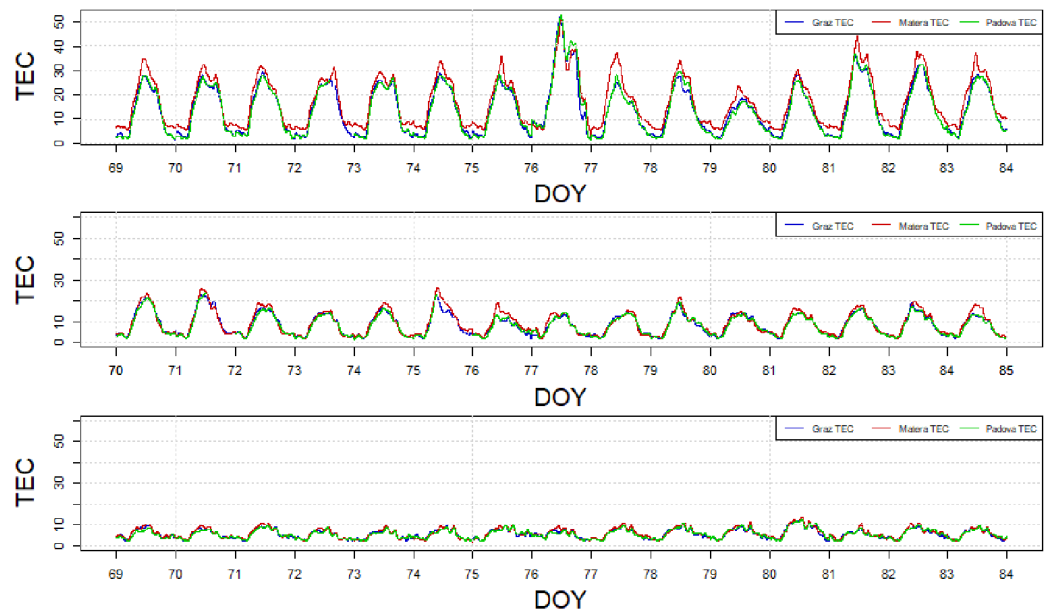

Figure 6 - TEC values measured in Graz, Matera and Padua in 2015 (top), 2016 (middle) and 2017 (bottom)

Interplanetary magnetic field components values were compared through all years (Figure 7). The highest span of component values was noted during 2015, a medium span during 2016, and the lowest span during 2017. The vertical component of interplanetary magnetic field $(\mathrm{Bz})$ indicated strong southward direction during geomagnetic storm 2015 reaching peak value of $-27.8 \mathrm{nT}$.
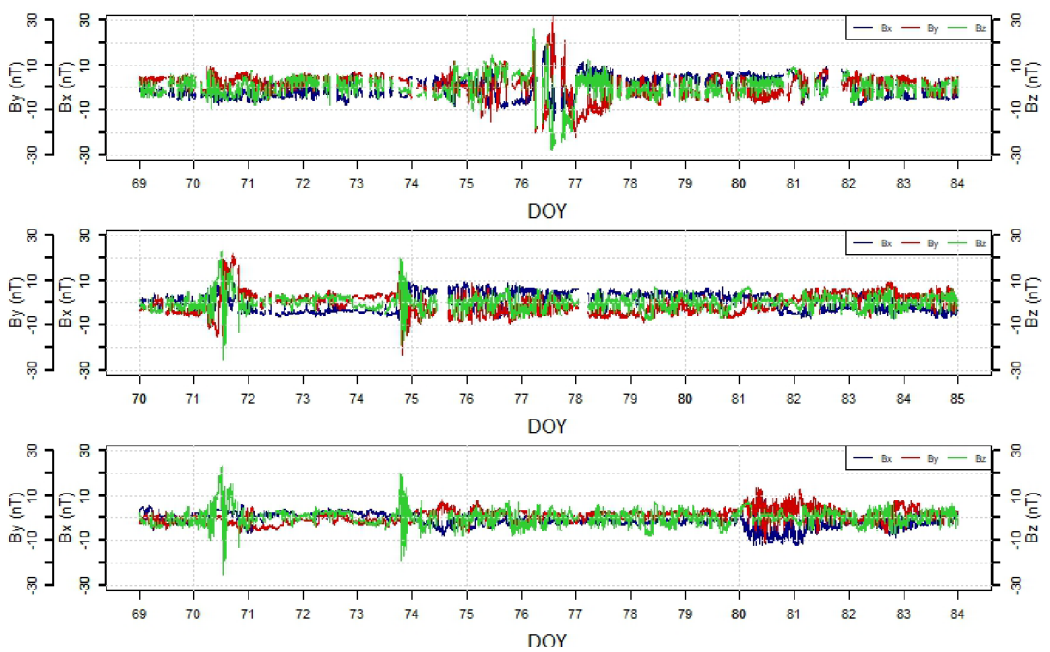

Figure 7 - Interplanetary magnetic field components (Bx, By, Bz) in 2015 (top), 2016 (middle) and 2017 (bottom) 
Overall Bz mean value during 2015 was $0.35 \mathrm{nT}$. During 71st day of year in 2016, IMF was also oriented strong southward but less than previous year with Bz value low as $-25.3 \mathrm{nT}$. The mean value of 0.19 indicated slight northward direction. During 70th day in $2017 \mathrm{Bz}$ component reached peak value of -17.9 indicating moderate southward direction. The mean value of 0.004 indicates no direction.

\subsection{GPS L1 positioning performance}

The correlation matrices of positioning errors between IGS stations are presented for each year (Figure 8). The size and color intensity of dots indicates the correlation value, while the color indicates whether the correlation is positive or negative (in this case, positive - blue). During disturbed conditions (in 2015) the positioning deviations between stations showed a strong correlation. Positioning errors of IGS stations Graz and Padua showed better mutual correlation than with IGS Matera.

When observing only significant correlations, the lowest value of the Pearson correlation coefficient was 0.64 between Matera longitude and Graz/Padua longitude positioning errors. The highest correlation was 0.92 between longitude errors between Graz and Padua. Pearson coefficient values of Graz and Padua are between 0.89 and 0.92 .

During 2016, similar correlation scenario was observed. A slightly stronger correlation was found between Matera and other two stations when compared to 2015, with the lowest coefficient value of 0.71 . The coefficient range was between 0.72 and 0.86 .

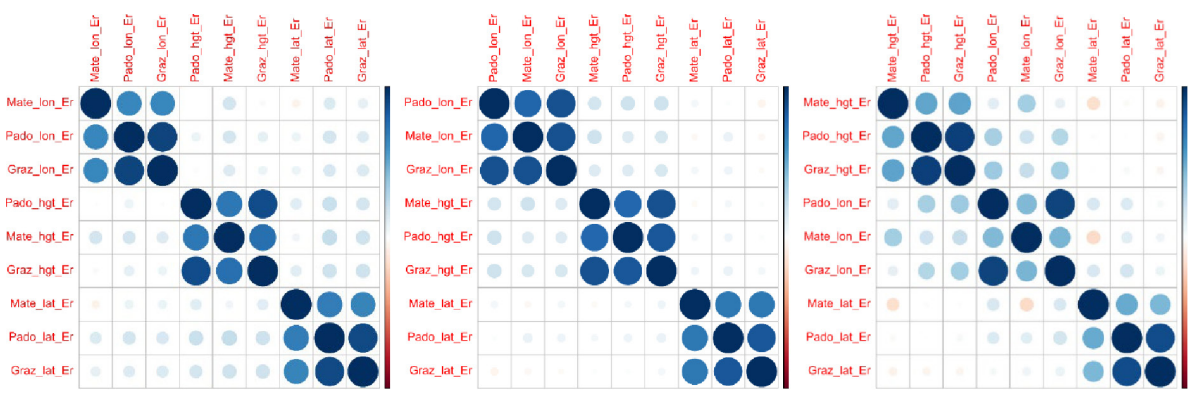

Figure 8 - Correlation of positioning errors in 2015 (left image), 2016 (middle image) and 2017 (right image)

During quiet space weather conditions, a significant correlation was observed between Graz and Padua in all three coordinates, particularly in height errors, reaching the value of 0.92. In Table 2, statistical description of positioning errors is shown. 
Table 2 - Positioning errors'statistical description (in meters)

\begin{tabular}{|c|c|c|c|c|c|c|c|c|}
\hline Station & Coordinate & Minimum & 1st Qtr. & Median & Mean & 3rd Qtr. & Maximum & $\begin{array}{l}\text { Standard } \\
\text { deviation }\end{array}$ \\
\hline \multicolumn{9}{|c|}{2015} \\
\hline \multirow{3}{*}{ Graz } & Latitude & -0.5794 & 3.5400 & 4.1680 & 4.1820 & 4.7580 & 11.1600 & 1.0767 \\
\hline & Longitude & -4.4140 & -1.7790 & -1.3510 & -1.3310 & -0.9222 & 3.5400 & 0.7566 \\
\hline & Height & -17.8100 & -0.2722 & 0.9718 & 0.9261 & 2.2150 & 20.5100 & 2.2390 \\
\hline \multirow{3}{*}{ Matera } & Latitude & -4.2160 & 0.3811 & 1.0120 & 1.0680 & 1.6950 & 7.3460 & 1.0620 \\
\hline & Longitude & -6.5890 & -0.2726 & 0.1999 & 0.2488 & 0.6615 & 9.4380 & 0.9451 \\
\hline & Height & -20.0000 & -2.5100 & -1.0260 & -1.0510 & 0.3101 & 22.2700 & 2.6436 \\
\hline \multirow{3}{*}{ Padua } & Latitude & -3.5760 & 0.5337 & 1.2280 & 1.2510 & 1.8110 & 9.2320 & 1.0992 \\
\hline & Longitude & -1.9010 & 0.1805 & 0.5627 & 0.5982 & 0.9606 & 4.8290 & 0.7061 \\
\hline & Height & -17.4500 & -2.3780 & -1.0500 & -1.1750 & 0.1735 & 18.0600 & 2.2353 \\
\hline \multicolumn{9}{|c|}{2016} \\
\hline \multirow{3}{*}{ Graz } & Latitude & -0.08301 & 3.27000 & 3.83700 & 3.80200 & 4.33000 & 6.9090 & 0.8298 \\
\hline & Longitude & -3.3830 & -1.7220 & -1.2870 & -1.2860 & -0.8605 & 1.7850 & 0.5675 \\
\hline & Height & -8.9090 & -0.5654 & 0.5781 & 0.6259 & 1.9650 & 8.0760 & 1.8855 \\
\hline \multirow{3}{*}{ Matera } & Latitude & -2.6780 & 0.1401 & 0.6534 & 0.6522 & 1.1270 & 4.6870 & 0.8234 \\
\hline & Longitude & -1.9250 & -0.1534 & 0.2501 & 0.2766 & 0.7026 & 3.2110 & 0.5959 \\
\hline & Height & -10.3600 & -2.9950 & -1.7490 & -1.6790 & -0.2585 & 6.2960 & 1.9724 \\
\hline \multirow{3}{*}{ Padua } & Latitude & -1.8790 & 0.4009 & 0.9422 & 0.8877 & 1.3630 & 4.0400 & 0.7726 \\
\hline & Longitude & -1.6100 & 0.3130 & 0.6771 & 0.6922 & 1.0780 & 3.9470 & 0.5362 \\
\hline & Height & -10.3100 & -2.57800 & -1.43600 & -1.35400 & -0.07813 & 5.71700 & 1.7680 \\
\hline \multicolumn{9}{|c|}{2017} \\
\hline \multirow{3}{*}{ Graz } & Latitude & 1.6090 & 3.5470 & 3.9590 & 3.9590 & 4.3680 & 6.9530 & 0.6597 \\
\hline & Longitude & -3.4860 & -1.7350 & -1.3700 & -1.3840 & -0.9945 & 0.4447 & 0.5344 \\
\hline & Height & -8.4840 & -0.7702 & 0.2598 & 0.2830 & 1.4350 & 5.7870 & 1.7516 \\
\hline \multirow{3}{*}{ Matera } & Latitude & -4.8510 & 0.2239 & 0.7250 & 0.7027 & 1.1820 & 9.3670 & 0.8038 \\
\hline & Longitude & -7.7460 & -0.2252 & 0.2363 & 0.2503 & 0.7340 & 9.5280 & 0.8262 \\
\hline & Height & -28.1800 & -3.1810 & -1.9310 & -1.8930 & -0.5497 & 15.8600 & 2.4960 \\
\hline \multirow{3}{*}{ Padua } & Latitude & -1.2800 & 0.6772 & 1.0700 & 1.0680 & 1.4560 & 3.4490 & 0.6446 \\
\hline & Longitude & -1.5660 & 0.2776 & 0.6216 & 0.6119 & 0.9800 & 2.4720 & 0.5310 \\
\hline & Height & -9.9040 & -2.6630 & -1.6310 & -1.6070 & -0.5703 & 4.1640 & 1.6561 \\
\hline
\end{tabular}

Analyses of solar, geomagnetic and ionospheric indices confirmed different levels of space weather activity during the elaborated periods. Satellite positioning performance analyses confirmed similar positioning errors' responses. Correlation results have justified those observations, which opened a possibility for the development of the model of positioning errors' estimation. 


\section{A regional model of positioning errors' estimation}

Positioning errors of IGS station Padua were used as a reference to estimate the positioning errors of IGS station Graz. Data from IGS Matera were not considered for model development since the correlation results of positioning performance were not as strong as between two other stations. The linear regression model has been developed for latitude (lat), longitude (lon) and height (h) errors for each year:

$$
\Delta y_{\text {Grazlat,lon, } h}=\hat{a}+\hat{b} \Delta x_{\text {Padolat, lon }, h}
$$

where $\Delta y_{\text {Grazlat,lon, } h}$ latitude, longitude or height absolute error at Graz, $\Delta x_{\text {Padolat, lon, },}$ latitude, longitude or height error at Padua, $\hat{a}, \hat{b}$... model coefficients.

Linear regression coefficients $\hat{a}, \hat{b}$ obtained for each coordinate error and year are presented in Table 3 .

Table 3 - Model coefficients

\begin{tabular}{c|cccccc}
\cline { 2 - 7 } & \multicolumn{7}{c}{ COEFFICIENTS } \\
\cline { 2 - 7 } & \multicolumn{2}{c}{ Latitude error } & \multicolumn{2}{c}{ Longitude error } & \multicolumn{2}{c}{ Height error } \\
\hline & $\hat{a}$ & $\hat{b}$ & $\hat{a}$ & $\hat{b}$ & $\hat{a}$ & $\hat{b}$ \\
2015 & 3.08 & 0.88 & -1.92 & 0.99 & 1.97 & 0.89 \\
2016 & 2.99 & 0.91 & -1.93 & 0.91 & 1.84 & 0.90 \\
2017 & 2.99 & 0.91 & -1.95 & 0.92 & 1.85 & 0.98 \\
\hline Mean & 3.02 & 0.90 & -1.93 & 0.94 & 1.89 & 0.92
\end{tabular}

Final model coefficients were calculated as average values of yearly coefficients. Averaging of coefficients was done to consider different space weather conditions, which were prevailing through elaborated years. In this way, positioning errors' estimation refers to space weather conditions in general, rather than for a particular level of activity.

The cross validation with five folds was carried out to validate the model's performance. On Figures 9-11, the calculated reference coordinate errors (Padua) are placed on axis, while the Graz coordinate errors are placed on axis.

Latitude cross validation residuals median was -0.0052 with coefficients values of 3.02 for intercept and 0.90 for Padua latitude error. The model showed good performance in latitude errors prediction with $\mathrm{R}$ squared value of 0.78 . 


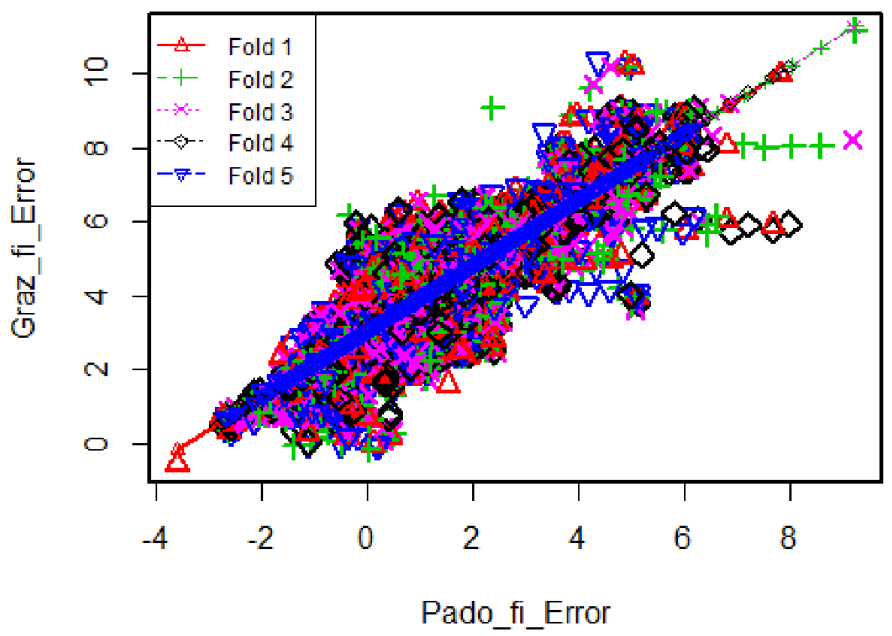

Figure 9-Latitude (fi) model cross validation results with five subsamples (folds)

Longitude cross validation residuals median was 0.0015 with coefficients values of -1.93 for intercept and 0.95 for Padua longitude error. The model showed good performance in longitude errors prediction with $\mathrm{R}^{2}$ value of 0.81 .

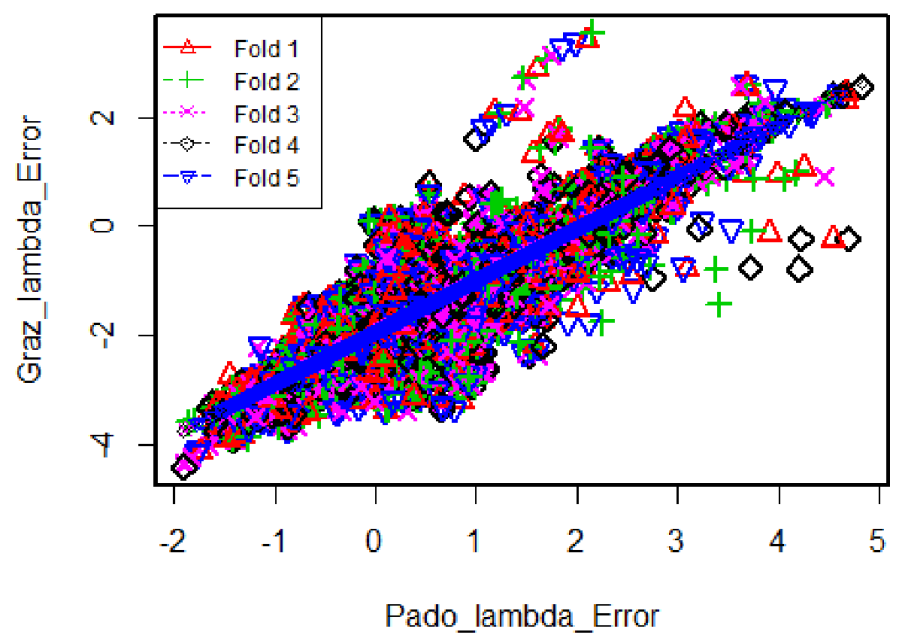

Figure 10 - Longitude (lambda) model cross validation results with five subsamples (folds)

Height cross validation residuals median was 0.0036 with coefficients values of 1.88 for intercept and 0.92 for Padua height error. The model showed good performance in height errors prediction with $\mathrm{R}^{2}$ value of 0.78 . 


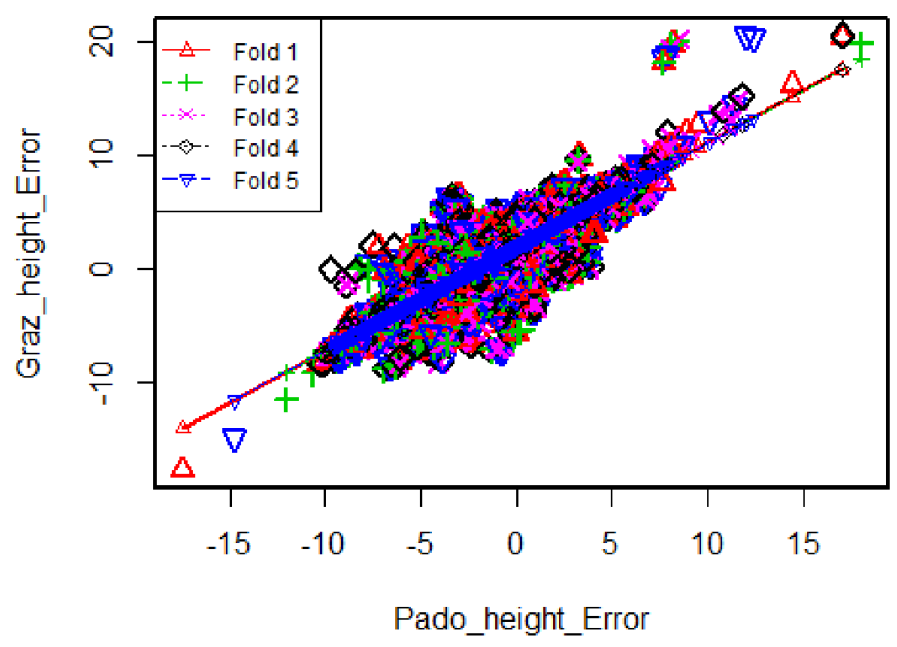

Figure 11 - Height model cross validation model results with five subsamples (folds)

Individual (annual) validation results are describing the model performance during the different level of space weather activity, while the average validation results indicate that the model performs satisfactorily when all levels of activity are encompassed as averages.

\section{Conclusions}

Analyses of different levels of space weather activity served as an environmental influence factor on the satellite positioning performance in the Adriatic Region. Further analyses confirmed the common behaviour of the satellite positioning performance between all elaborated ground truth data in the Adriatic region. Given its vicinity, IGS Graz and IGS Padua showed the stronger correlation in positioning error behaviour and therefore were used for the rudimentary positioning errors' estimation model development.

The validation results showed that the model performed well in the estimation of positioning errors during quiet, moderate and disturbed space weather conditions, as defined with representative indices. This approach represents a preliminary means of positioning errors estimation based on known satellite positioning performance at specific area where reference stations does not exist. The final model coefficients, encompassing all levels of space weather activity confirmed model's applicability regardless of the state of the environment.

Although the initial tendency was to employ a broader area for the model development, it has been found that the positioning errors from IGS Matera deviated differently than at two other sites. This difference can be explained with farther 
distance and southern location of the IGS Matera when compared to IGS Graz and IGS Padua. The exact definition of the common influence radius remains a subject for the forthcoming research, as well as for further development of the proposed model in terms of multiple GNSS locations' employment and positioning errors' response to outer impacts in the middle latitude region.

\section{Acknowledgments}

This work has been supported by the University of Rijeka under the project - uniritehnic 18-66. Authors appreciate and support the access to open software tools: $R, R$ Studio, RTKLIB and Rinex-GPS-TEC, as well as the official databases containing GNSS observables and indices describing space weather activity. This research wouldn't be possible without this valuable data.

\section{References}

1. Hunsucker, R.D. and Hargreaves, J. K., Eds. (2003). The high-latitude ionosphere and its effects on radio propagation; Cambridge University Press, Cambridge, UK.

2. Schunk, R. and Nagy, A. (2009). Ionospheres: Physics, Plasma Physics and Chemistry, 2nd ed.; Cambridge University Press: Cambridge, UK.

3. Filjar, R., Brčić, D. and Kos, S. (2013). Single-frequency Horizontal GPS Positioning Error response to a moderate Ionospheric storm over Northern Adriatic. In Weintrit, A., Ed.; Advances in Marine Navigation. CRC Press: London. pp. 49-56.

4. Toman, I., Kos. S. and Brčić, D. (2019). On long-term solar activity impact on GPS singlefrequency 3D positioning accuracy in the Adriatic Region. In Proceedings of 12th Annual Baška GNSS Conference, Baška, Croatia, 7-9 May 2018. The Royal Institute of Navigation: London, UK \& University of Rijeka, Faculty of Maritime Studies: Rijeka, Croatia. pp. 27-49.

5. Pongračić, B., Kos. S. and Brčić, D. (2019). Spatial assessment of GPS ionospheric delay model during St. Patrick's geomagnetic storm. In Proceedings of 11th Annual Baška GNSS Conference, Baška, Croatia, 7-9 May 2018; The Royal Institute of Navigation: London, UK \& University of Rijeka, Faculty of Maritime Studies: Rijeka, Croatia. pp. 75-91.

6. Takasu, T. (2019). RTKLIB: An Open Source Program Package for GNSS Positioning. Available at: www.rtklib.com [Accessed 22 May 2019].

7. International GNSS Service (IGS). (2019). IGS observations archive and products. Available at: http://www.igs.org [Accessed 5 May 2019].

8. US National Geodetic Survey (US NGS). (2019). Continuously Operating Reference Stations (CORS): GPS navigation messages in RINEX format. Available at: https://www.ngs.noaa.gov/ CORS/standard1.shtml [Accessed 10 May 2019].

9. International GNSS Service (IGS). (2019). The Receiver INdependent EXchange Format (RINEX). Available at: https://kb.igs.org/hc/en-us/articles/115003864627-RINEX-3-01 [Accessed 22 April 2019].

10. International Real-Time Magnetic Observatory Network (INTERMAGNET). (2018). Available at: http://www.intermagnet.org/index-eng.php [Accessed 8 October 2018].

11. World Data Center for Geomagnetism Kyoto (WDC). (2019). Available at: http://wdc.kugi.kyoto-u. ac.jp/index.html [Accessed 18 October 2019].

12. Sunspot Index and Long-term Solar Observations (SILSO). (2019). Available at: http://sidc.be/ silso/home [Accessed 18 October 2019].

13. Space Physics Data Facility (SPDF). (2019). Available at: https://omniweb.gsfc.nasa.gov/hw.html [Accessed 25 October 2019]. 
14. Moldwin, M. (2008). An Introduction to Space Weather. Cambridge University Press, Cambridge, UK.

15. Echer, E., Gonzalez, W. D. and Alves, M. V. (2006). On the geomagnetic effects of solar wind interplanetary magnetic structures. Space Weather: The International Journal of Research and Applications, 4(6), pp. 1-11.

16. National Oceanic and Atmospheric Association's Space Weather Prediction (NOAA SWCP). (2018). NOAA Space Weather Scales. Available at: https://www.swpc.noaa.gov/noaa-scalesexplanation [Accessed 24 October 2018].

17. Rodgers, J. L. and Nicewander, W. A. (1988). Thirteen Ways to Look at the Correlation Coefficient. The American Statistician. Available at: https://www.stat.berkeley.edu/ rabbee/correlation.pdf [Accessed 11 March 2019].

18. Stone, M. (1974). Cross-validatory choice and assessment of statistical predictions. Journal of Royal Statistical Society, 36(2), pp. 111-147. 